\title{
La paradoja de la verticalización y gentrificación versus la integración de la ciudadanía
}

\section{Jorge Inzulza-Contardo}

ORCID: https://orcid.org/0000-0003-4578-4550

Departamento de Urbanismo, Universidad de Chile, Santiago, Chile. Correo electrónico: jinzulza@uchilefau.cl

Los procesos de cambio socioespacial con disparidades territoriales continúan en un repunte sin precedente, afectando los cielos urbanos de todo el mundo y, de manera acelerada, a nuestro continente latinoamericano. Tanto las ciudades metropolitanas, como de escala intermedia y menores, se están viendo fuertemente desafiadas ante la falta de regulación urbana que controle la excesiva altura de edificación, principalmente de proyectos inmobiliarios y sus procesos asociados como el reemplazo de población original y pérdida de identidad local (Inzulza Contardo \& López Irías, 2014).

Para ilustrar esta situación, presentamos a continuación tres trabajos que buscan una mirada crítica en esta materia. El primero de ellos, explora en la incidencia de las normas de excepción en la planificación de la verticalización del Área Metropolitana de Santiago. Magdalena Vicuña y Marcela Moraga entregan desde un punto de vista cuantitativo, el impacto que las normas de fusión predial, conjunto armónico y Decreto de Fuerza de Ley (DFL) N N $^{\circ}$ en la constructibilidad del proyecto residencial en altura en barrios verticalizados del AMS, están incidiendo en el potencial edificatorio del proyecto residencial en altura y con una falta evidente de planificación urbana local frente a disposiciones centralizadas y que ya poseen más de cinco décadas de aplicación.

Esta problemática metropolitana es reforzada, además, con el trabajo de Rodrigo Vidal y, en particular, con el controversial caso de la comuna de Estación Central. El autor pone en debate el impacto de los permisos de edificación de 80 torres de más de 20 pisos en esta comuna, entre 2013 y 2018, con una afectación directa de conos de sombra sobre las relaciones de continuidad y distanciamiento, las condiciones de ventilación, la presencia de vegetación y el parque automotriz que satura el entorno construido y afecta la calidad de vida de sus residentes. De la misma forma, la radiación solar y la planificación urbana es reforzada con el caso de Bahía Blanca, en Argentina. María Eugenia Fernández y Jorge Gentili, mediante un análisis nutrido sobre la distribución espaciotemporal de la radiación solar a escala urbana y su vinculación con elementos naturales y antropogénicos. Los autores entregan un análisis de la distribución temporal de la Radiación Solar Global (RSG) dentro del período 2000-2019 y su vinculación con las coberturas nubosas, lo que, sin duda, permite avanzar en temas de diseño urbano que incluyan una adecuada vegetación y orientación de sus elementos urbanos.

En un segundo grupo de trabajos, se presentan las siguientes tres investigaciones que ponen en evidencia procesos de gentrificación principalmente desde la acción inmobiliaria, tanto en el centro como la periferia urbana. Gonzalo Rodríguez retrata la acción de grandes proyectos urbanos en Buenos Aires dentro del periodo 1991-2010. Mediante la construcción de indicadores cuantitativos que miden gentrificación y desplazamientos, el autor entrega evidencias de esta problemática, con menos desplazamientos asociados al entorno de los grandes proyectos, pero más intenso en el norte de la ciudad. Esta visión se traslada a Chile y se focaliza en los modos de habitar en el contexto periurbano de Santiago.

\section{CÓMO CITAR ESTE ARTÍCULO:}

Inzulza-Contardo, J. (2021). La paradoja de la verticalización y gentrificación versus la integración de la ciudadanía. Revista de Urbanismo, (45), 1-3. https://doi.org/10.5354/0717-5051.2021.65578 
Víctor Suazo y Andrea Cárdenas nos ofrecen una mirada crítica etnográfica en megaproyectos residenciales del tipo condominios cerrados que muestran transformaciones en la vida cotidiana. Víctor y Andrea evidencian dimensiones claves de transformación sobre la movilidad cotidiana, la sociabilidad, las actividades cotidianas y la convivencia vecinal, que se relacionan con el rol de los holdings inmobiliarios en la configuración de las periferias y sus efectos modeladores sobre los modos de habitar las metrópolis contemporáneas.

Por su parte, Luis Salinas y Lisette Soto nos brindan una mirada aguda sobre la dualidad - empresas inmobiliarias y gobiernos locales - en la construcción masiva de vivienda en la periferia de la ciudad de México y las implicaciones a nivel local de los acuerdos para los procesos de autorización de conjuntos urbanos en municipios de la Zona Metropolitana de dicha ciudad. Luis y Lisette concluyen que existe consenso post-político que se construye desde la normativa impuesta por parte de organismos internacionales y gobierno federal y las propias tensiones entre los distintos niveles de gobierno y las empresas inmobiliarias.

En contraposición, un tercer grupo de investigaciones entrega un aporte a la integración social y el rol de la ciudadanía contemporánea. Se abre con el análisis de Mariana Dondo, Héctor Civitaresi, Laura Valeo y María Nussbaum sobre los instrumentos de participación pública en plusvalías urbanas para la ciudad de Bariloche, Argentina. Centrado en dos casos de estudio en esta ciudad - nueva terminal de ómnibus y la obra del puente del Ñireco - se concluye que los instrumentos normativos pueden contribuir a obtener recursos para financiar el desarrollo urbano y aportan a una estructura de financiamiento de los gobiernos locales más equitativa.

Esta mirada sobre el gobierno local para aplicar mecanismos y promover un desarrollo de las ciudades más equitativo, también es compartida en el trabajo de Ignacio Tiznado-Aitken y Clemente Larraín, quienes plantean un análisis de los criterios para definir áreas de integración urbana en Chile. Generando una simulación de estos criterios en la ciudad capital, con datos abiertos y herramientas SIG, los autores evalúan si son suficientes para asegurar una adecuada accesibilidad al transporte público y al equipamiento urbano y capacidad de carga apropiada para la densificación. Basado en este último trabajo, este tipo de análisis es muy pertinente para avanzar propuestas y lineamientos que debieran incluirse al momento de definir áreas para la densificación con cuotas de vivienda social. En una dimensión más sensitiva, Isabel Donetch pone en valor el arraigo de las comunidades, por medio de una metodología con un nuevo enfoque para la puesta en valor de los sitios de memoria de Chile. A partir de la una revisión documental exhaustiva, se aborda el estudio del Parque por la Paz Villa Grimaldi, para entender cómo diferentes comunidades valoraban este sitio. La autora concluye que para asegurar la sustentabilidad de los sitios de memoria a futuro, es necesario la inclusión de las perspectivas de los diferentes actores sociales en la puesta en valor de estos lugares.

Dentro de los actores sociales claves, la población infantil aparece como un desafío para el urbanismo contemporáneo, lo que es relevado en el trabajo de Carla Hermida, Gabriela Naranjo, Jaime Peña, Adriana Quezada y Daniel Orellana, por medio de la relación entre la movilidad activa a la escuela y el entorno urbano. Haciendo una revisión de la literatura científica de los años 2009-2019 incluida en la base de datos bibliográfica Scopus, las y los autores poden en evidencia que las decisiones del colegio vienen principalmente de los padres, con problemáticas asociadas a la inseguridad vial y personal, así como con condiciones sociodemográficas de los barrios, la distancia y el clima. Esta problemática se relaciona además al trabajo de Orlando Ipiña y Carlos Peña respecto a la inserción de proyectos de impacto barrial en la ciudad de México, buscando incentivar la cooperación de las colonias y barrios de alta marginalidad en el desarrollo de proyectos que fomentan las actividades deportivas y lúdicas en el espacio público como el programa de gimnasios urbanos y mejoramiento barrial.

Los resultados de esta última investigación permiten, además, epilogar el presente número, dando énfasis a que los procesos sociales actuales están emplazando, de alguna forma, los usos originales de lo público que 
normalmente provienen de agendas estatales y premisas más tradicionales. En ese sentido, las nuevas formas de apropiación que obedecen más a las necesidades de la comunidad y, no a un discurso político, están siendo alertada por organismos globales (Banco Mundial, 2021; CEPAL, 2020) que han puesto en la palestra la necesidad de mayor conocimiento situado - de abajo hacia arriba - y la integración social que represente la ciudadanía latinoamericana.

\section{Referencias bibliográficas}

Banco Mundial (2021). América Latina y el Caribe: panorama general. Disponible en https://www. bancomundial.org/es/region/lac/overview\#1

CEPAL, Comisión Económica para América Latina y el Caribe (2020). Panorama Social de América Latina. Santiago: Naciones Unidas. ISBN: 978-92-1-004758-6.

Inzulza Contardo, J., \& López Irías, N. (2014). Gentrificación de escala intermedia global en Latinoamérica. El caso de la reconstrucción de Managua, Nicaragua 1972-2014. Revista de Urbanismo, (31), 56-75. doi:10.5354/0717-5051.2014.33274. 